\title{
Identificação de investimentos em eficiência energética e sua avaliação de risco
}

\author{
Identification of energy efficiency investments and \\ their risk assessment
}

\author{
Carolina Salazar Aragón ${ }^{1}$ \\ Edson Pamplona ${ }^{2}$ \\ Juan Ricardo Vidal Medina ${ }^{3}$
}

\begin{abstract}
Resumo: Para se obter economia de energia por meio da melhoria da eficiência energética, é necessário fazer um diagnóstico que mostre o real desempenho energético e, assim, determinar os investimentos requeridos. Não obstante, a viabilidade econômica destes investimentos deve ser avaliada. Diversos autores afirmam que esta área é carente, especialmente na avaliação do risco. O payback é o critério mais utilizado, mas não é o mais conveniente. O objetivo deste trabalho é aplicar uma metodologia que envolve duas análises: a análise de engenharia e a análise de risco. A análise de engenharia é feita por meio do uso de ferramentas de diagnóstico que permitem identificar os investimentos em eficiência energética. A análise de risco permite avaliar sua viabilidade, considerando a incerteza associada às variáveis que determinam a economia de energia e seu efeito sobre estas, adaptando a metodologia $\mathrm{EBaR}^{\circledR}$ por meio da modelagem e simulação. A metodologia proposta foi aplicada em uma empresa do setor industrial brasileiro e permitiu identificar que a empresa pode diminuir o consumo não associado à produção em até $60 \%$, e que o investimento proposto para melhorar a eficiência energética é viável, pois apresenta uma boa relação retorno-risco.
\end{abstract}

Palavras-chave: Diagnóstico energético. Eficiência energética. Investimento. Risco.

\begin{abstract}
In order to achieve energy savings through improvements in energy efficiency, an energy diagnosis that shows the actual energy performance and determines the investments required is necessary. Nevertheless, the viability of these investments should be evaluated. The aim of this study is to adopt a method that involves two analyses: engineering analysis and risk analysis. Engineering analysis is conducted through the use of diagnostic tools to identify energy efficiency investments. Risk analysis enables the evaluation of the feasibility of these investments considering the uncertainty associated with the variables that determine energy savings and the effect on them, adapting the $E B a R^{\circledR}$ approach through modeling and simulation. The method proposed was applied to a company in the Brazilian industrial sector and indicated that the company can reduce the consumption of non-production related energy by $60 \%$, and that the investment proposed to improve energy efficiency is feasible since it has a good risk-return-ratio.
\end{abstract}

Keywords: Energy diagnostic. Energy efficiency. Investment. Risk.

\section{Introdução}

As novas tecnologias não convencionais e renováveis que poderiam diminuir a poluição ambiental, por enquanto inviabilizam a mudança das tecnologias que vêm sendo utilizadas desde o início da era industrial, visto o seu alto custo e a quantidade de tempo que esta mudança requereria. Desta forma, deve-se procurar um equilíbrio sustentável entre as tecnologias novas e a adequada exploração das convencionais. Assim, a eficiência energética (EE) surge como uma boa alternativa para diminuir a poluição ambiental, além de melhorar a produtividade e a competitividade das empresas. Esta melhoria é obtida em consequência da diminuição do consumo de energia, que se reflete em menores custos de operação. Como apresenta Cicone et al. (2007), a eficiência energética é uma medida fundamental para

\footnotetext{
${ }^{1}$ Mestrado Engenharia de Produção, Instituto de Engenharia de Produção e Gestão - IEPG, Universidade Federal de Itajubá - UNIFEI, Av. BPS, 1303, 50, 37500-903, Itajubá, MG, Brasil, e-mail: casaragon@ hotmail.com

2 Engenharia de Produção, Instituto de Engenharia de Produção e Gestão - IEPG, Universidade Federal de Itajubá, UNIFEI, Av. BPS, 1303, 50, 37500-903, Itajubá, MG, Brasil, e-mail:pamplona@unifei.edu.br

3 Grupo de Investigación en Energías - GIEN, Departamento de Energética y Mecánica, Facultad de Ingeniería, Universidad Autónoma de Occidente - UAO, Km 2, Via Cali, Jamundí, Cali, Valle del Cauca, Colombia, e-mail: jrvidal@uao.edu.co
}

Recebido em 23/8/2012 — Aceito em 30/11/2012

Suporte financeiro: Nenhum. 
manter um crescimento saudável nas empresas por meio de instalações mais eficientes.

As empresas têm interesse em investir em projetos de eficiência energética e obter seus benefícios econômicos, porém estas enfrentam duas dificuldades: a correta identificação dos investimentos necessários para melhorar a eficiência energética; e a avaliação do risco para estes investimentos.

Quanto à primeira, as empresas geralmente desconhecem ferramentas para a identificação correta dos projetos. Isto é, os projetos se focam na simples troca de equipamentos sem levar em conta fatores como a relação produção-consumo, energia não associada à produção e índices de consumo que refletem os verdadeiros custos energéticos (CAMPOS, 2004), o que significa que as empresas esquecem o real significado de eficiência. Quanto à segunda, como todos os investimentos, estes também estão condicionados à disponibilidade de capital, e o retorno também é afetado pelo risco. Porém, a falta de conhecimento na avaliação deste tipo de investimentos e a adoção de critérios que, apesar de serem convencionais não são os mais apropriados para levar em conta o risco, têm levado os tomadores de decisões a rejeitar opções de investimentos em eficiência energética que trazem benefícios (JACKSON, 2008; DeCANIO, 1998). Por outro lado, Mills et al. (2006) e Tuomaala, Hurme e Leino (2010) afirmam que é necessária uma análise robusta dos aspectos físicos da eficiência energética para a correta tradução destes dados físicos na linguagem dos investimentos, pois muitos dos investimentos relacionados com energia são feitos sem uma clara compreensão dos seus valores financeiros, riscos e volatilidades (MILLS et al., 2006). Ainda, Härus (2009) afirma que as barreiras dos investimentos em EE se derivam de uma mesma razão: a falta de ferramentas adequadas de análise. Por esta razão, o autor destaca que é necessária a clara compreensão dos benefícios dos investimentos em EE para não serem rejeitados apesar de serem rentáveis. Logo, é necessário conciliar as duas análises, a de engenharia e a econômica. Deste modo, é necessário conhecer ferramentas que permitam fazer uma correta análise de engenharia, ou seja, um correto diagnóstico energético para obter valores mais confiáveis sobre a economia de energia que podem ser atingidas e, também, entender os benefícios que a eficiência energética traz. Além disso, é importante conhecer os fatores que causam incerteza sobre esta economia, para que, baseando-se nestes dados, possa ser feita a análise econômica e a avaliação de risco, porém com ferramentas apropriadas para este tipo de investimentos.

Assim, considerando também que foi lançada a nova norma ISO 50001, correspondente à implantação de Sistemas de Gestão de Energia, cujo foco é a eficiência energética, se propõe uma metodologia que concilia as duas análises antes mencionadas, para compreender os aspectos físicos da eficiência energética e traduzi-los na linguagem dos investimentos.
Deste modo, para o desenvolvimento da pesquisa, primeiro é discutida a avaliação dos investimentos em eficiência energética e o uso das ferramentas de avaliação para este tipo de investimentos e, depois, se descreve passo a passo a metodologia proposta por meio de uma aplicação real em uma empresa do setor industrial brasileiro. Esta metodologia está composta por duas análises: a de engenharia e a econômica e de risco. A primeira é desenvolvida com auxílio das ferramentas de gestão de energia propostas pela Unidad de Planeación Minero Energética (UPME) do Ministério de Minas e Energia da Colômbia; as quais permitem a caracterização energética, a quantificação da economia de energia e os investimentos necessários para melhorar o desempenho energético. A segunda permite avaliar a viabilidade desses investimentos considerando o risco, pela modelagem e simulação e adaptando a ferramenta $\mathrm{EBaR}^{\circledR}$. Apresentam-se, assim, estas duas análises em um só trabalho. Em grande parte dos artigos pesquisados que propõem alguma metodologia de avaliação de risco, como os de Jackson (2010), Mills et al. (2006) e Mathew et al. (2005), não se mostra como foram determinados os investimentos. Além disso, estes trabalhos têm sido focados aos investimentos em eficiência energética do sistema de climatização, que inclui aquecimento, ventilação e ar condicionado (HVAC) de edifícios, sendo necessário fazer a análise para outros contextos de uso de energia, como o industrial, em que há um grande volume de equipamentos que utilizam este recurso.

\section{Investimentos em eficiência energética}

Os investimentos em EE são considerados como parte do processo de tomada de decisões sobre o orçamento de capital (HÄRUS, 2009), portanto, e de acordo com EPA (ENVIRONMENTAL..., 1998), os investimentos em EE devem ser considerados como qualquer outro investimento, o que significa que têm que ser avaliados com as mesmas ferramentas de avaliação econômica, além de uma análise de risco. Porém, um investimento em EE difere de outros investimentos porque as suas receitas são geradas pela economia de energia e não pelas atividades que constituem o core business da empresa.

Assim, Biezma e San Cristobal (2006) afirmam que o VPL, a TIR e o payback são os critérios mais utilizados para avaliar investimentos em EE, apesar de existirem numerosos critérios. Segundo EMTF (ENERGY..., 2006), o payback e o retorno sobre o investimento (ROI) são as regras $a d$ hoc para a avaliação de investimentos em EE, mas que podem levar a decisões erradas, enquanto que a TIR e o VPL são mais efetivos.

Em trabalhos mais recentes, Jackson (2010) e Elliott, Shipley e McKinney (2008) afirmam que, na prática, a metodologia mais utilizada para avaliar investimentos em EE é o payback, além de que é 
utilizado como uma simples regra de decisão para reduzir o risco, por limitação da análise a períodos de recuperação curtos (JACKSON, 2010). Resultados similares foram encontrados anteriormente por Ross (1986) Sua pesquisa encontrou que os tomadores de decisão só investem em projetos de eficiência energética cujo investimento inicial é recuperado no máximo em um ano, sendo este um fator que causa o baixo investimento em eficiência energética (DeCANIO, 1993).

Pode-se concluir que o payback é a metodologia de avaliação mais utilizada na tomada de decisões sobre investimentos em eficiência energética, pois as decisões baseadas em períodos curtos de recuperação supõem menos incerteza. Porém, seu uso é questionado por suas desvantagens, sendo uma das razões para a existência da lacuna da eficiência energética, dada pela barreira criada pela limitação das análises a períodos curtos de recuperação do investimento, devido à falta de metodologias de avaliação mais sofisticadas e precisas. É por isso que a análise de risco é uma das áreas de avaliação de investimentos em eficiência energética na qual se deve dar ênfase e melhorar as ferramentas de análise (HÄRUS, 2009)

\subsection{Análise de risco de investimentos em eficiência energética}

A eficiência energética por si só já tem sido promovida como uma ferramenta de gestão de risco para reduzir os efeitos da volatilidade dos preços no mercado de energia (NAUMOFF; SHIPLEY, 2007; RUSSELL, 2005), mas, mesmo assim, investir em EE traz consigo incertezas sobre a economia de energia que se podem gerar.

Thompsom (1997) afirma que o risco dos investimentos em eficiência energética está relacionado com a incerteza do preço do combustível e a incerteza dos consumos atuais e futuros, pois um equipamento antigo pode apresentar variações nos consumos na medida em que envelhece, enquanto que para o novo equipamento pode não haver um registro de consumo bem estabelecido.

EPA (ENVIRONMENTAL..., 1998) afirma que o risco dos investimentos em eficiência energética está relacionado com a estimativa dos custos futuros da energia e com os custos de operação e manutenção, ou seja, com as suposições assumidas durante a vida do projeto, porém afirma que estes investimentos, em comparação com outros, são considerados de risco baixo. Entretanto, Sandberg e Söderström (2003) concluíram que as empresas pesquisadas têm um alto grau de aversão ao risco.

Sob a ótica do investidor, a fragilidade dos investimentos em eficiência energética está na falta de modelos quantitativos de risco e na sua análise (MATHEW et al., 2005). Deste modo, sugerem que os riscos e a rentabilidade dos investimentos em eficiência energética sejam analisados e avaliados da mesma forma que outros projetos de investimento. Mas para conhecer os riscos que afetam estes investimentos é necessária uma análise robusta dos aspectos físicos da eficiência energética, ou seja, é necessária sua compreensão para a correta tradução destes dados físicos na linguagem dos investimentos (MILLS et al., 2006; TUOMAALA; HURME; LEINO, 2010).

Quanto à incerteza, Mills et al. (2006) encontraram que há diferentes fontes de risco nos investimentos em EE, além de outras fontes que afetam a capacidade de gestão do risco. Deste modo, os autores classificaram os riscos em cinco categorias: econômicos, contextuais, tecnológicos, operacionais e de medida e verificação, por meio de uma matriz, considerando os fatores endógenos e exógenos que afetam às categorias. Mills et al. (2006) afirmam que a comunidade financeira tem técnicas bem estabelecidas para a avaliação de riscos e que muitas destas podem ser aplicadas à avaliação dos investimentos em eficiência energética, tais como: a simulação de Monte Carlo e o coeficiente de variação.

\subsection{Energy budgets at risk - EBaR ${ }^{\circledR}$}

Com o propósito de melhorar a análise de risco para os investimentos em eficiência energética, Jackson (2008) desenvolveu uma ferramenta chamada Energy Budgets at Risk $\left(\mathrm{EBaR}^{\circledR}\right)$. Ela é baseada em Value at Risk - VaR, que é uma ferramenta de gestão de riscos utilizada pelo setor financeiro. O coração de $\mathrm{EBaR}^{\circledR}$ é a análise de Monte Carlo, considerada a mais poderosa no cálculo do valor do risco (JORION, 1998).

Variáveis como o clima, o desempenho dos equipamentos e o preço da energia estão sujeitos à incerteza. Assim, a EBaR ${ }^{\circledR}$ faz uma análise dos dados e das possíveis variações de cada uma das variáveis e as aplica em uma simulação de Monte Carlo, a qual, simultaneamente, incorpora as influências das variáveis no investimento, como apresentado na Figura 1, e fornece uma distribuição de probabilidade para TIR e a economia líquida gerada se for feito o investimento em eficiência energética.

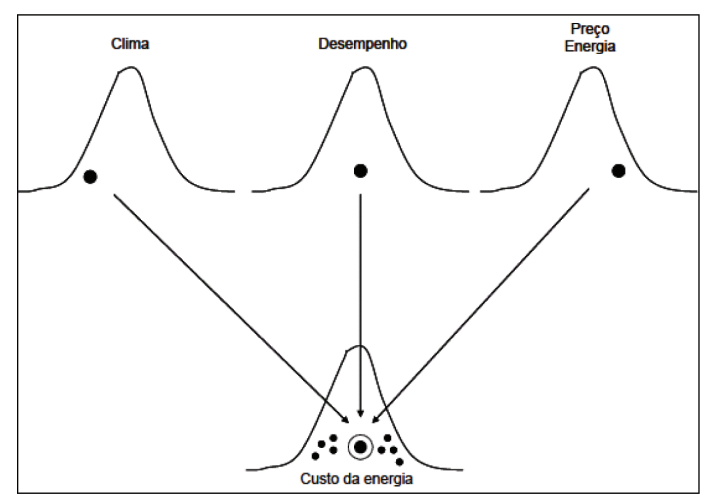

Figura 1. Estrutura da Análise de Monte Carlo. Fonte: Adaptada de Jackson (2010). 
Em termos gerais, o que a ferramenta $\mathrm{EBaR}^{\circledR}$ permite fazer é uma caracterização quantitativa da incerteza dada pelas variáveis que influenciam a economia de energia usando a simulação de Monte Carlo. Em outras palavras, mede a probabilidade de ocorrência dos cenários menos atrativos para os critérios de avaliação de investimentos, permitindo tomar decisões condicionadas pela tolerância ao risco de uma organização, pois, se considerado apenas o resultado de cada critério, não está se avaliando o risco gerado pela incerteza das variáveis antes mencionadas.

Cabe destacar que as diferentes aplicações feitas pelo autor da metodologia $\mathrm{EBaR}^{\circledR}$ têm sido em objetos de estudo como prédios de escritórios privados e do governo, restaurantes, escolas, supermercados, hotéis, hospitais e igrejas. Ou seja, para locais onde são focadas as análises aos sistemas de ventilação, calefação, ar condicionado e iluminação. Para o caso proposto nesta pesquisa, é adotada e adaptada a metodologia $\mathrm{EBaR}^{\circledR}$ para uma empresa industrial do setor metal-mecânico.

\section{Diagnóstico energético e avaliação de investimentos de eficiência energética em uma empresa do setor industrial brasileiro}

O desenvolvimento deste diagnóstico, que determina os investimentos necessários para melhorar a eficiência energética e sua respectiva avaliação de risco, é realizado por meio da metodologia resumida no fluxograma da Figura 2.

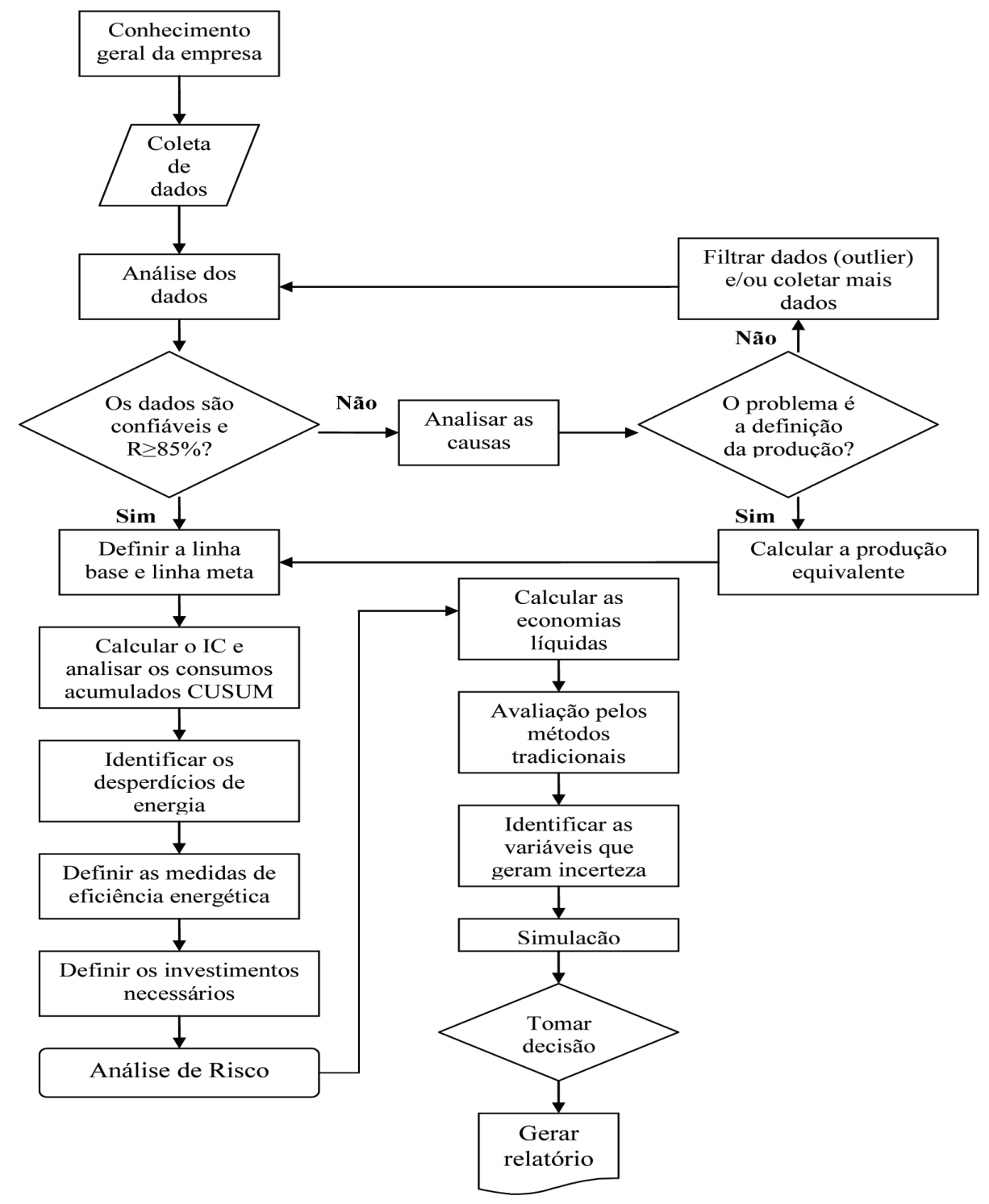

Figura 2. Fluxograma para identificação e avaliação de investimentos em eficiência energética. A empresa na qual se realizou o diagnóstico energético fabrica componentes de motores. Está localizada na cidade de Itajubá, Minas Gerais, Brasil. Esta empresa está dividida em unidades ou minifábricas, e o diagnóstico energético é feito na minifábrica de buchas e arruelas. 


\subsection{Diagnóstico energético}

\subsubsection{Primeiro passo: conhecimento geral da empresa e da unidade a ser analisada}

Quanto à gestão da energia, a empresa tem uma política energética e entre seus objetivos está reduzir os custos pela diminuição do consumo de energia em 2,5\%, sendo que, para conseguir esta redução, tem como projetos: iluminação eficiente, bancos de capacitores e reaproveitamento de água da Estação de Tratamento de Efluentes (ETE). Porém, esta meta foi determinada pela média do consumo do último ano e não com indicadores ou ferramentas adequadas que refletem seu real desempenho energético, além de que a empresa não realizou nenhuma auditoria energética, seja interna ou externa.

A minifábrica opera 24 horas por dia, durante 365 dias do ano com três turnos de 8 horas cada, incluindo uma hora de recesso em cada turno.

A tarifa da energia no horário de ponta é de $\mathrm{R} \$ 36,81$ e, no horário fora de ponta, de $\mathrm{R} \$ 6,13$ por $\mathrm{kW}$ e uma tarifa de consumo de $\mathrm{R} \$ 0,15289024$ por $\mathrm{kWh}$.

$\mathrm{Na}$ minifábrica analisada, em média, o consumo mensal por demanda no horário de ponta é de $1040 \mathrm{~kW}$ e de 1137 kW no horário fora de ponta. A manutenção das máquinas está focada na disponibilidade e não em critérios de eficiência e otimização energética e produtiva.

\subsubsection{Segundo passo: coleta de dados}

Considerando as variáveis a serem analisadas, são coletados os dados de consumo de energia (kWh) e produção (unidades) mensal durante o período 2008-2010. Esta atividade pode ser feita juntamente com as atividades do primeiro passo.

\subsubsection{Terceiro passo: análise dos dados}

A análise dos dados é feita pelas ferramentas propostas por UPME (UNIDAD..., 2006) apresentadas de 3.1.3.1 a 3.1.3.5

\subsubsection{Gráfico de controle}

Este gráfico é feito para avaliar a variável objeto de estudo, neste caso, o consumo. Como o propósito deste gráfico é analisar se o comportamento da variável está dentro dos limites estabelecidos, são calculados a média, o desvio padrão e os limites central inferior e superior. Estes dados são apresentados na Tabela 1 e são utilizados para construir o gráfico de controle apresentado na Figura 3.

É possível analisar que, aparentemente, a variável consumo está sob controle, pois seu comportamento está dentro dos limites estabelecidos, porém há pontos de distribuição anormais, ao se observar um comportamento de tendência com subidas e quedas que se mantém durante um período de tempo.

Tabela 1. Estatísticos para construir o gráfico de controle.

\begin{tabular}{lr}
\hline Média $-\mu$ & $476.077,06$ \\
Desvio padrão $-\sigma$ & $129.999,18$ \\
LCS & $866.074,61$ \\
LCI & $86.079,50$ \\
\hline
\end{tabular}

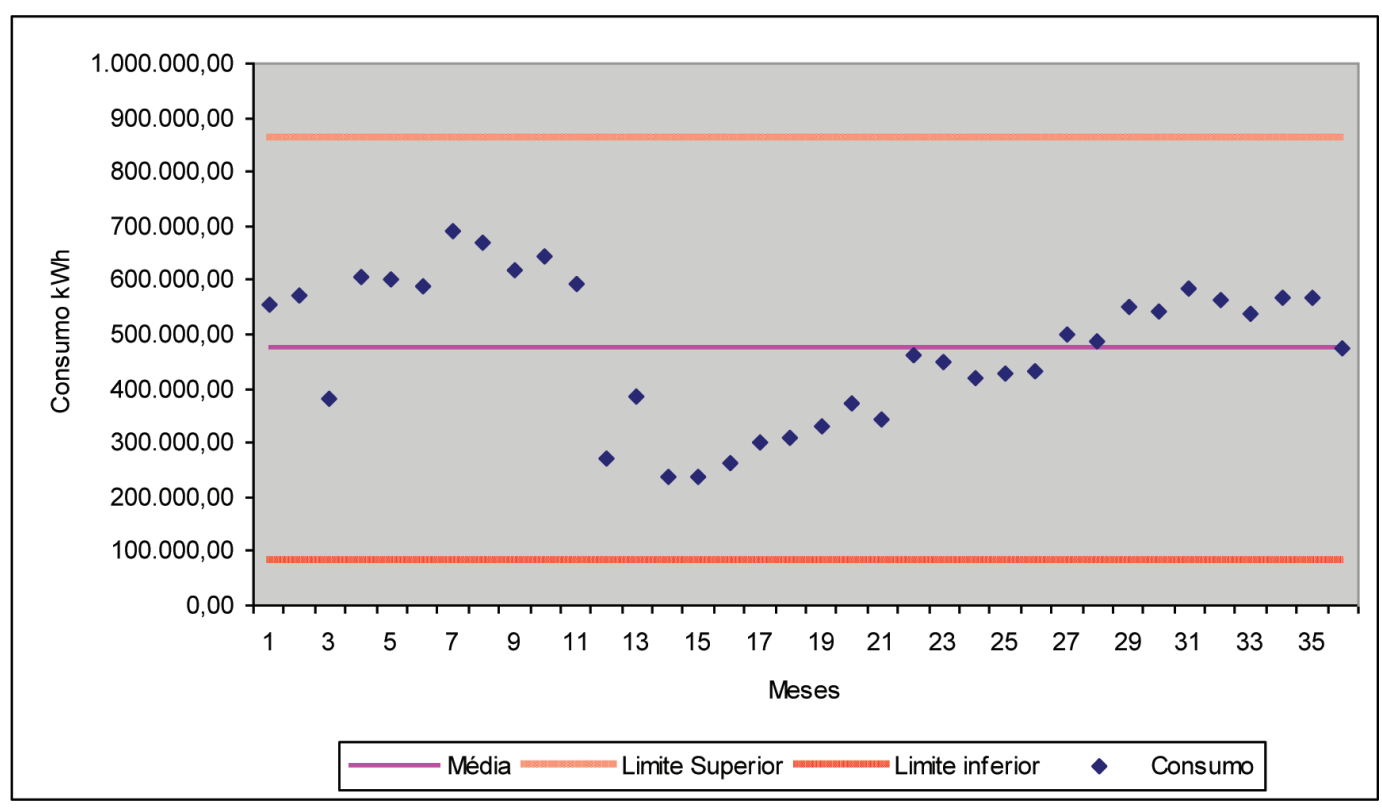

Figura 3. Gráfico de controle para o consumo de energia. 


\subsubsection{Diagrama de consumo e produção versus tempo}

Pela Figura 3, é possível determinar que existem vários períodos que apresentam comportamentos anormais, pois apresentam-se intervalos em que, apesar de a produção aumentar, o consumo diminui. Levando-se em conta que são apresentados muitos comportamentos anormais durante o período analisado, é necessário determinar a confiabilidade dos dados. Esta confiabilidade é calculada segundo a seguinte equação proposta por UPME (UNIDAD..., 2006) (Equação 1):

$\frac{\text { No. }- \text { de-pares }- \text { de }- \text { dados }- \text { com - comportamento - normal }}{\text { No. }} * 100$ (1)

Substituindo os dados na Equação 1, temos:

$$
\frac{18}{36} * 100=50 \%
$$

De acordo com a classificação dada por UPME (UNIDAD..., 2006), o resultado obtido classifica-se como confiabilidade deficiente. Este resultado, juntamente com o comportamento irregular observado na Figura 4, mostra indícios de que existem inconsistências nos dados.

\subsubsection{Análise de correlação consumo vs. produção}

Esta análise é feita por meio do valor $r$, que, para a variável objeto de estudo, é 0,7657 . Segundo UPME (UNIDAD..., 2006), se $\mathrm{r} \leq 0,85$, há uma correlação fraca e, portanto, os dados não refletem a real eficiência da área analisada.
Levando em conta os resultados das análises anteriores, são estudadas as possíveis causas que estão gerando o comportamento das variáveis. De acordo com CEEMA (CENTRO..., 2002) e UPME (UNIDAD..., 2006), as razões mais frequentes que causam uma correlação fraca entre as variáveis podem ser:

- erros na medição, coleta e processamento dos dados;

- o consumo de energia não é controlado adequadamente e as práticas de operação e manutenção estão pobremente definidas;

- os períodos para os quais foram medidos o consumo e a produção não são iguais;

- o termo produção não foi claramente definido, pois podem existir produtos em processo que consumiram energia, mas não considerados, produtos com diferentes requerimentos energéticos ou fatores ou atividades que influenciam no consumo e não se refletem na produção.

Seguindo estas pautas, encontra-se que a minifábrica define sua produção como o total de unidades produzidas, sem levar em conta que há dezesseis linhas de produção, cada uma com requisitos energéticos diferentes. Logo, para fazer o diagnóstico e conhecer a real eficiência da minifábrica, deve ser calculada a produção equivalente, a qual permite incorporar à produção os fatores ou atividades que têm uma influência significativa no consumo e que normalmente não são considerados.

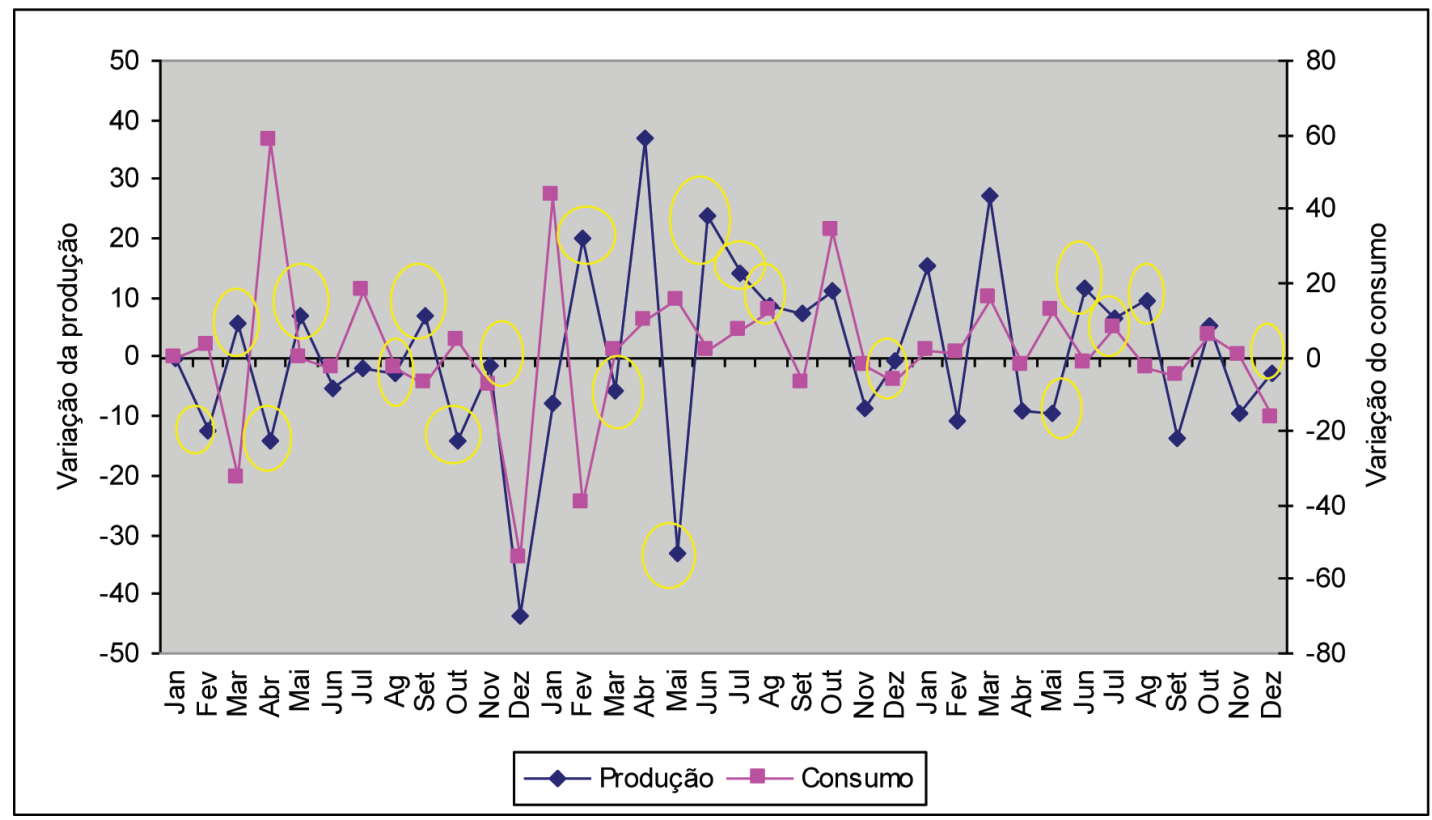

Figura 4. Diagrama produção - consumo vs. Tempo. 
A equação da produção equivalente está dada por (Equação 2):

$$
\sum U i^{*} F i
$$

em que: $U i$ são as unidades produzidas em cada linha; Fi é o fator de conversão energético para cada linha; Para o cálculo do fator de conversão energético, é necessário definir uma das linhas como linha base, e o consumo de cada linha vai ser dividido pelo consumo da linha base. Assim, o fator de conversão energético para cada linha está dado pela Equação 3:

$$
F_{i}=\frac{C i}{C_{\text {base }}}
$$

em que: $F_{\mathrm{i}}$ é o fator de conversão para cada linha; $C_{\mathrm{i}}$ é o consumo de energia de cada linha por unidade produzida; $C_{\text {base }}$ é o consumo de energia da linha base por unidade produzida

Para determinar a linha base, analisou-se o consumo energético de cada linha por unidade e encontrou-se que a linha de maior consumo é a linha B09, portanto, está é a linha escolhida como base. Substituindo os valores da produção mensal de cada linha e seu respectivo fator de conversão energético na Equação 3, é possível expressar a produção da minifábrica em unidades equivalentes da linha B09. O novo coeficiente de correlação é 0,8766 .

\subsubsection{Determinação da linha base e a linha meta de consumo}

Solucionado o problema de correlação das variáveis por meio da produção equivalente, é possível determinar a linha base e a linha meta de consumo. A linha base indica o comportamento atual da minifábrica e a linha meta é o que pode ser alcançado se melhorar sua eficiência energética.

Com auxílio do Modelo de Regressão Linear Simples, é possível determinar a equação para o consumo $C$. A equação que o descreve é (Equação 4):

$$
C=E_{0}+m^{*} P
$$

Esta equação apresenta dois coeficientes de regressão importantes para a análise energética: a inclinação $m$ corresponde à razão de câmbio, meio do consumo de energia em relação à produção, ou seja, que $m * P$ representa o consumo de energia utilizada no processo produtivo; a interseção $E_{0}$ é o consumo de energia não associada à produção, o que quer dizer que, se a empresa não produzir, mesmo assim, há um consumo de energia. Muito da economia de energia pode estar naquele consumo não associado à produção e, segundo UPME (UNIDAD..., 2006), este consumo pode estar dado por:

- a iluminação da usina;

- a eletricidade para equipamentos dos escritórios;
- as áreas acondicionadas tanto de aquecimento quanto de resfriamento;

- a energia usada durante os serviços de manutenção;

- o pré-aquecimento dos equipamentos e sistemas de tubulações;

- a energia perdida em ar comprimido.

A equação da linha base ou consumo base, $C_{\mathbf{b}} \mathrm{em}$ função da produção equivalente $P_{\text {eq }}$ fica (Equação 5):

$$
C_{b}=44.861+0,396 * P_{e q}
$$

Pode-se concluir que a minifábrica tem um consumo de energia não associado à produção de 44.861 kWh por mês.

A linha meta é determinada com os pontos que estão debaixo da linha base, os quais representam os melhores desempenhos de consumo - produção da minifábrica, como apresentado na Figura 5. Ao se determinar a linha de regressão para estes pontos, é obtida a linha meta, para a qual a equação da linha meta ou consumo meta $C_{\mathbf{m}}$ está dada pela Equação 6 .

$$
C_{m}=17.832+0,396 * P_{\text {metaeq }}
$$

A diferença entre a linha base e a linha meta determina o potencial de economia de energia da minifábrica, que, neste caso, é de $27.029 \mathrm{kWh}$ por mês e $324.348 \mathrm{kWh}$ ao ano, o que significa que a minifábrica pode reduzir o consumo não associado à produção até em $60 \%$. Outro aspecto importante é que a inclinação $m$ das duas linhas é igual, o que quer dizer que a minifábrica pode melhorar sua eficiência com os recursos disponíveis, ou seja, não precisa trocar tecnologia.

\subsubsection{Diagrama de tendência dos consumos energéticos acumulados (CUSUM)}

Para a realização do diagrama CUSUM é necessário:

- definir um período base de comparação;

- obter para o período base a equação do consumo por meio do método dos mínimos quadrados;

- na equação obtida, substituir P pelo valor da produção do período atual, isto é, o consumo de energia no período base se a produção houvesse sido igual à produção do período atual;

- calcular a diferença entre o consumo do período atual e o consumo do período base obtido no passo 3;

- calcular a soma acumulativa da diferença do consumo calculado no passo anterior.

Este diagrama representado pela Figura 6, permite observar que a minifábrica apresenta uma tendência a aumentar seu consumo energético em relação ao período base (ano 2009), o que indica que é 
necessário tomar medidas para conseguir melhorar este comportamento. Este diagrama é útil tanto antes quanto depois de implantar alguma medida de eficiência energética, pois, antes, permite visualizar a tendência do consumo energético da empresa diante do período base e, depois, é útil para monitorar a efetividade da medida.

\subsubsection{Quarto passo: identificar onde estão os desperdícios de energia}

Para identificar os desperdícios de energia, é necessário analisar as áreas de maior consumo e fazer uma vistoria. Neste trabalho, são apresentados os resultados da vistoria. Assim, foi possível perceber que os operadores da minifábrica não têm consciência do uso racional da energia, pois, na hora de recesso de cada turno, as máquinas permanecem ligadas mesmo sem estar produzindo, o que se reflete naquele consumo não associado à produção. $\mathrm{O}$ mesmo acontece nas salas do pessoal administrativo da minifábrica, pois, ao sair da sala, não são desligados computadores e/ou lâmpadas. Também foi verificada a presença de vazamentos de ar comprimido em quase todas as máquinas. Embora para garantir o fluxo de ar comprimido seja necessário o uso de energia elétrica, este fato não foi levado em consideração pela falta de medições, porém, em trabalhos futuros, pode ser feita uma análise para quantificar estes desperdícios e determinar os potenciais de economia de energia.

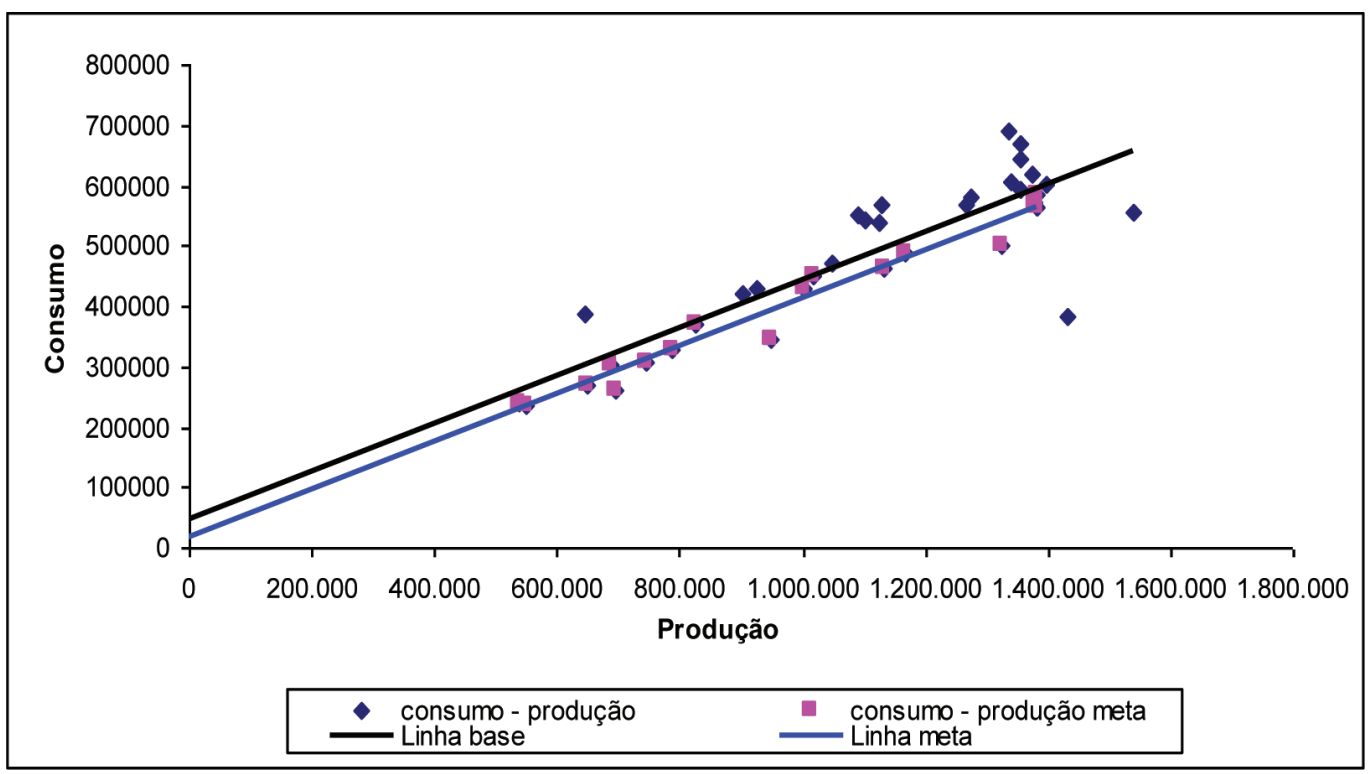

Figura 5. Linha base e linha meta.

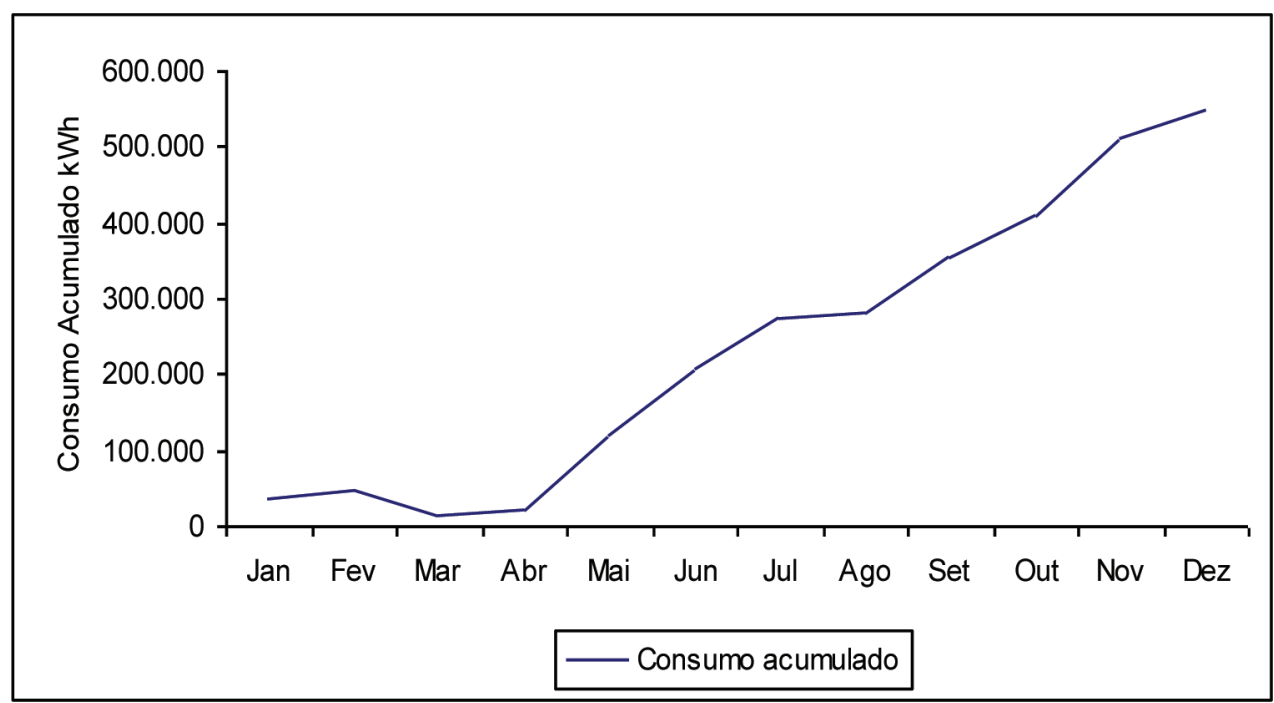

Figura 6. Diagrama de CUSUM. 
De acordo com a vistoria feita, os desperdícios de energia estão dados principalmente por:

- máquinas e lâmpadas ligadas no horário de recesso de cada turno;

- lâmpadas e computadores das salas administrativas ligados no horário de almoço.

\subsubsection{Quinto passo: identificação das medidas de eficiência energética}

Como se apresentou nos resultados obtidos, ao estimar a linha meta a minifábrica pode melhorar sua eficiência e diminuir o consumo energético com a mesma tecnologia instalada, significando que não são necessários investimentos em novas máquinas. Assim, as medidas de eficiência energética que contribuem para atingir este potencial de economia são medidas de baixo custo, tais como:

- campanhas de conscientização sobre o uso racional da energia, com o propósito de que as lâmpadas do galpão sejam desligadas na hora do almoço, igualmente lâmpadas e computadores das salas de embalagem e do pessoal administrativo;

- operação e manipulação eficiente das máquinas,

- manutenção focada para melhorar a eficiência das máquinas;

- automatização do desligamento das máquinas quando não estiverem em funcionamento, como na hora de recesso de cada turno.

Para o desenvolvimento deste trabalho, será analisada a medida de automatização das máquinas.

A minifábrica opera 24 horas do dia, 365 dias ao ano. Para sua operação, estão definidos três turnos, sendo cada um de oito horas, incluindo uma hora de recesso em cada turno. Esta hora de recesso é chave para a economia de energia, pois, como se constatou, os operadores não desligam as máquinas enquanto estão no horário de recesso, o que significa que a minifábrica pode ter economia de energia durante três horas do dia. $\mathrm{O}$ processo consiste em programar as máquinas para se autodesligarem depois de determinado tempo sem produzir. Operando estas máquinas durante 21 horas por dia consegue-se uma economia de $11.723 \mathrm{kWh}$ ao mês e $140.676 \mathrm{kWh}$ ao ano, ou seja, só com esta medida é possível alcançar $43 \%$ do potencial de economia que a minifábrica tem.

\subsubsection{Sexto passo: definir os investimentos necessários}

De acordo com informação do engenheiro responsável pela minifábrica, para este processo só é necessário um engenheiro para programar cada máquina. Os dados do investimento são apresentados na Tabela 2.

\subsubsection{Sétimo passo: análise de risco}

Este processo é feito adaptando a metodologia $\mathrm{EBaR}^{\circledR}$ para simular com Crystal Ball ${ }^{\circledR}$ cada uma das opções de investimentos.

\subsubsection{Calcular a economia líquida}

Este passo corresponde à determinação do fluxo de caixa de um projeto, com a diferença de que o fluxo de caixa dos investimentos em EE está dado pela economia líquida de energia gerada pela implantação da medida de EE. Para isto, primeiro deve ser calculada a economia de energia, a qual corresponde à diferença entre o consumo atual e o consumo se a medida for implantada, porém expressada em termos monetários. A economia de energia está dada pela Equação 7.

$$
\text { Economia }=\left(C_{A_{-}} k W h * T\right)-\left(C_{F_{-}} k W h * T\right)
$$

em que: $\mathrm{C}_{\mathrm{A}}=$ consumo em $\mathrm{kWh}$ atual, ou seja, sem a medida de eficiência energética; $\mathrm{C}_{\mathrm{F}}=$ consumo em kWh se implantar a medida de eficiência energética; $\mathrm{T}=$ tarifa paga pelo consumo $\mathrm{R} \$ / \mathrm{kWh}$.

Para a tarifa de energia, utilizou-se a tarifa por consumo de energia e a tarifa por demanda no horário de ponta e fora de ponta. Deste modo, a tarifa total de energia é de $0,236326 \mathrm{R} \$ / \mathrm{kWh}$. Substituindo os valores de consumo mensal das máquinas e a tarifa na Equação 7, a economia mensal de energia gerada pelo projeto são:

$$
\begin{aligned}
& \text { Economia }=(93.782 * 0,236326)-(82.059 * 0,236326) \\
& \text { Economia }=2.770,38
\end{aligned}
$$

Deste modo, a automatização das máquinas gera economia de $\mathrm{R} \$ 2.770,38$ por mês, o que significa economia anual de $\mathrm{R} \$ 33.244,50$.

Depois devem ser descontadas e/ou somadas as despesas e/ou economia correspondentes à operação e manutenção. Ou seja, uma medida de eficiência energética pode gerar despesas, mas também pode ser que economize. Para o caso da automatização das máquinas, se prevê a manutenção anual, que consiste em uma atualização. Deste modo, estima-se uma nova automatização a cada ano. Considerando as despesas por manutenção da automatização $\left(c_{\mathrm{m}}\right)$, é determinada a economia líquida de energia $\left(E_{1}\right)$, como apresentado na Tabela 3.

Tabela 2. Dados de investimento - Projeto A.

\begin{tabular}{lc} 
Número de máquinas & 27 \\
Valor/hora programador & $\mathrm{R} \$ 100$ \\
Tempo necessário por máquina & 2 horas \\
Investimento total & $\mathbf{R} \$ \mathbf{5 . 4 0 0}$ \\
\hline
\end{tabular}




$$
E_{l}=e e-c_{m}
$$

\subsubsection{Cálculo pelos métodos tradicionais}

O fluxo de caixa de cada projeto, dado pela economia líquida pode ser avaliado pelos métodos tradicionais como VPL e Payback. Na Tabela 4, são apresentados os dados do investimento.

\subsubsection{Análise das variáveis de incerteza}

As principais fontes de incerteza que devem ser consideradas nos investimentos em eficiência energética, segundo Jackson (2008), são as variáveis tarifa de energia, clima e desempenho dos equipamentos. Para o investimento proposto, será considerada a tarifa de energia. De acordo com Jackson (2008), podem ser utilizados os dados históricos para identificar a distribuição de probabilidade que descreve as variáveis de incerteza. Ao fazer esta análise para a tarifa, verificou-se uma tendência estacionária, coincidindo com as afirmações de Brandão (2010) e Zhou et al. (2009), as quais, levando em conta esta característica, propõem modelar esta variável por meio de uma distribuição normal. Deste modo, a tarifa de energia será modelada com uma distribuição normal $\operatorname{com} \mu=\mathrm{R} \$ 0,260769$ e $\sigma=\mathrm{R} \$ 0,034473$.

\section{Simulação}

Considerando o modelo para o cálculo da economia líquida de energia da Equação 8 e definidos estas últimas e o VPL, como as variáveis de prognóstico, e a tarifa de energia, como a variável de incerteza, é feita a simulação com Crystal Ball ${ }^{\circledR}$. Adotando a metodologia EBaR ${ }^{\circledR}$ são obtidos os resultados apresentados na Tabela 5 e nas Figuras 7 e 8 .

Segundo os resultados apresentados na Tabela 5 e nas Figuras 4 e 5, existem $90 \%$ de probabilidade de obter economia líquida maior ou igual a $\mathrm{R} \$ 25.067,25$ e um VPL maior ou igual a $\mathrm{R} \$ 89.466,58$, se a

Tabela 3. Economia líquida gerada pelo projeto A.

\begin{tabular}{lcrrrrrr}
\hline & $\mathbf{0}$ & $\mathbf{1}$ & $\mathbf{2}$ & $\mathbf{3}$ & $\mathbf{4}$ & $\mathbf{5}$ & $\mathbf{6}$ \\
\hline Investimento & $5.400,00$ & & & & & & \\
Economia de energia & & $33.244,50$ & $33.244,50$ & $33.244,50$ & $33.244,50$ & $33.244,50$ & $33.244,50$ \\
Manutenção & & $5.400,00$ & $5.400,00$ & $5.400,00$ & $5.400,00$ & $5.400,00$ & $5.400,00$ \\
Economia Líquida & & $-5.400,00$ & $27.844,50$ & $27.844,50$ & $27.844,50$ & $27.844,50$ & $27.844,50$ \\
\hline
\end{tabular}

Tabela 4. Avaliação dos investimentos pelos métodos tradicionais.

\begin{tabular}{lc}
\hline Investimento & 5.400 \\
Economia líquida & $27.844,50$ \\
VPL & $99.977,04$ \\
Payback & 0,2 \\
\hline
\end{tabular}

Tabela 5. Análise $\mathrm{EBaR}^{\circledR}$ para as medidas de eficiência energética propostas.

\begin{tabular}{lcc}
\hline & Economia Líquida & VPL \\
\hline Esperado & $27.844,50$ & $99.977,04$ \\
$90 \%$ & $25.067,25$ & $89.466,58$ \\
$95 \%$ & $23.296,71$ & $82.766,00$ \\
$97,50 \%$ & $21.738,75$ & $76.869,91$ \\
\hline
\end{tabular}

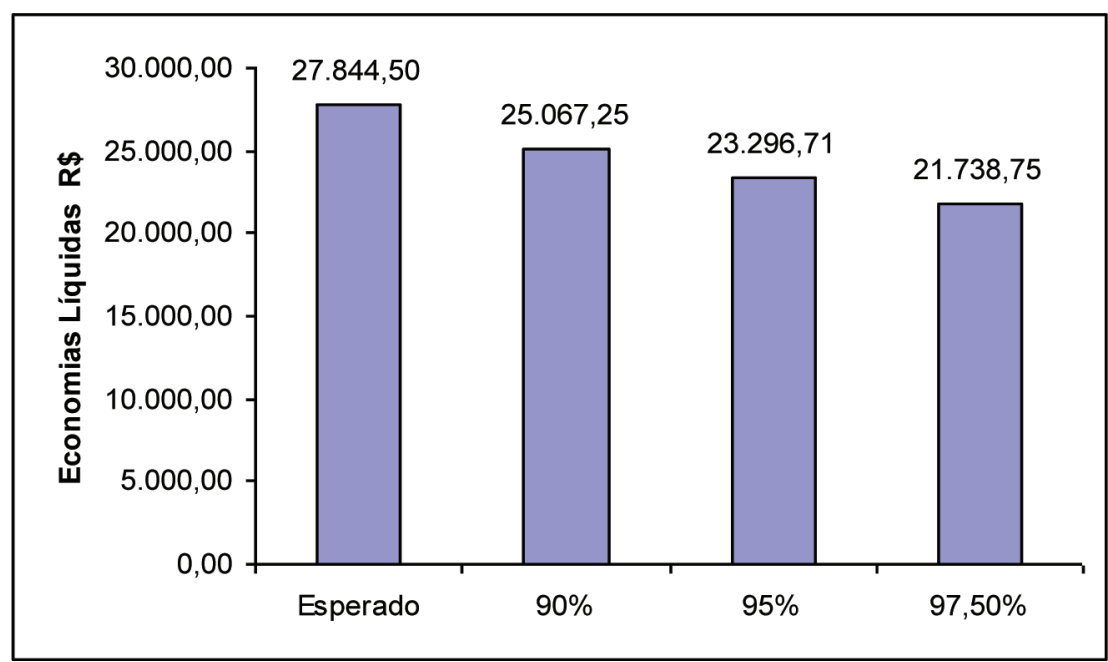

Figura 7. Economia líquida gerada pela medida de EE proposta. 


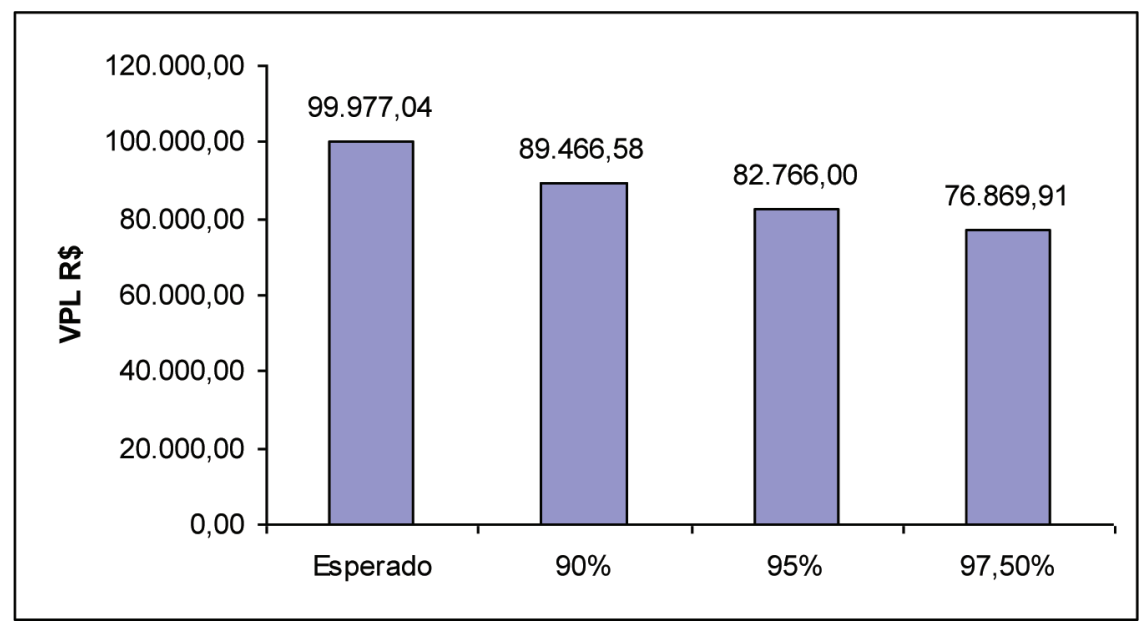

Figura 8. VPL da medida de EE proposta.

minifábrica automatizar as máquinas. No pior dos casos, existem $2,5 \%$ de probabilidade de obter economia líquida menor ou igual a $\mathrm{R} \$ 21.738,75$ e um VPL menor ou igual R $\$ 76.869,91$, caso seja implementada esta medida.

\section{Conclusões}

As empresas fixam seus objetivos de redução do consumo de energia por apreciações, como o caso da empresa diagnosticada, e não com uma justificativa técnica baseada no resultado de uma análise que possibilite avaliar seu desempenho energético por meio de indicadores que permitam relacionar as variáveis consumo e produção; o que leva os gestores da energia a focar os investimentos em eficiência energética na troca de equipamentos sem conhecer o verdadeiro desempenho energético da empresa, o qual ainda contribui para obter resultados não desejados e, portanto, a perceber estes investimentos como de alto risco.

Um bom diagnóstico energético contribui para minimizar os riscos tecnológicos, de operação, medição e verificação ao permitir fazer a caracterização energética que vai revelar as reais necessidades de melhora e as oportunidades de economia de energia com os recursos disponíveis, o que significa que uma correta análise de engenharia vai proporcionar dados confiáveis para a análise econômica e de risco, pois uma incorreta estimativa da economia pode subestimar ou sobrestimar uma medida de eficiência energética. É neste contexto que a metodologia proposta torna-se uma boa opção para conciliar as duas análises e permite aos gestores de energia e tomadores de decisões conhecerem os aspectos técnicos e econômicos da eficiência energética.

Quanto à análise de risco para os investimentos em eficiência energética, apesar de ser muito utilizado o payback, este não é o critério mais adequado para avaliar o risco ao não serem consideradas as variáveis que geram incerteza neste tipo de investimentos. É por isso que a adoção de metodologias como $\mathrm{EBaR}^{\circledR}$, com o uso do Crystal Ball ${ }^{\circledR}$, permite aos tomadores de decisões terem uma visão mais abrangente e precisa sobre o risco dos investimentos em eficiência energética.

Segundo o diagnóstico energético feito, a minifábrica pode reduzir em até $60 \%$ seu consumo de energia não associado à produção. E, de acordo com a avaliação de risco, a medida de eficiência energética analisada é um investimento que apresenta uma boa relação retorno-risco.

Por fim, a metodologia proposta pode ser aplicada em diferentes contextos, considerando, é claro, as características de cada situação.

\section{Referências}

BIEZMA, M.V.; SAN CRISTOBAL, J. R. Investment criteria for the selection of cogeneration plants-a state of the art review. Applied Thermal Engineering, v. 26 p. 583-588, 2006. http://dx.doi.org/10.1016/j. applthermaleng.2005.07.006

BRANDÃO, M. Análise dos parâmetros que influenciam a obtenção do valor da flexibilidade por Opções Reais no Setor Elétrico. 2010. Tese (Mestrado em Engenharia de Produção)-Universidade Federal de Itajubá, Itajubá, 2010. p. 69.

CAMPOS, J. C. Caracterizacion Energetica: el primer paso hacia el uso racional de la energia. Publicaciones Científicas. Revista Ciencias.com, 6 feb. 2004. Disponível em: <http://www.revistaciencias.com/ publicaciones/EpZyEkkEuulBycVxCr.php>. Acesso em: 29 out. 2010.

CENTRO DE ESTUDIOS DE ENERGIA Y MEDIO AMBIENTE - CEEMA. Gestión energética empresarial. Cuba: Universidad de Cienfuegos, 2002. 98 p. 
CICONE, D. et al. Atratividade financeira e tomada de decisão em projetos de eficiência energética. Revista Brasileira de Energia, v. 13, n. 2, p. 129-146, 2007

DeCANIO, S. J. Barriers within firms to energy-efficient investments. Energy Policy, v. 21, n. 9, p. 906-914, 1993. http://dx.doi.org/10.1016/0301-4215(93)90178-I

DeCANIO, S. J. The efficiency paradox: Bureaucratic and organizational barriers to profitable energy-saving investments. Energy Policy, v. 26, n. 5, p. 441-454, 1998 http://dx.doi.org/10.1016/S0301-4215(97)00152-3

ENERGY MANAGEMENT TASK FORCES - EMTF. Guide for the selection of energy Efficient Technologies. Saskatchewan, 2006. 24 p. Disponível em: <http://www.emtfsask.ca/pdfs/gdenefftech.pdf>. Acesso em: 06 nov. 2010.

ENVIRONMENTAL PROTECTION AGENCY - EPA. Business Analysis for Energy-Efficiency Investments. EPA, June 1998. 12 p.

ELLIOTT, R.; SHIPLEY, A.; McKINNEY, V. Trends in industrial investment decision making. American Council for an Energy Efficient Economy, Sept 2008. 23 p.

HÄRUS, N. Analyzing energy efficiency investments in the process industry - case Sachtleben Pigments Oy. 2009. 119 f. Tesis (Maestria)-Helsinki School of Economics, Helsinki, 2009.

JACKSON, J. Promoting energy efficiency investments with risk management decision tools. Energy Policy, v. 38, n. 8, p. 3865-3873, 2010. http://dx.doi.org/10.1016/j. enpol.2010.03.006

JACKSON, J. Energy budgets at risk. A energy management approach to energy purchase and efficiency choices. Wiley Finance, 2008. 300 p.

JORION, P. Value at risk: a nova fonte de referência para o controle do risco de mercado. São Paulo: Bolsa de Mercadorias \& Futuros, 1998. 305 p. PMid:9633118.

MATHEW, P. et al. Actuarial pricing of energy efficiency projects: lessons foul and fair. Energy Policy, v. 33, p. 1319-1328, 2005 http://dx.doi.org/10.1016/j. enpol.2003.12.008
MILLS, E. et al. From volatility to value: analysing and managing financial and performance risk in energy savings projects. Energy Policy, v. 34, p. 188-199, 2006 http://dx.doi.org/10.1016/j.enpol.2004.08.042

NAUMOFF, C.; SHIPLEY, A. M. Industrial energy efficiency as a risk management strategy. In: INDUSTRIAL ENERGY TECHNOLOGY CONFERENCE, 2007, New Orleans. Proceedings... New Orleans, 2007. 6 p.

ROSS, M. Capital budgenting practices of twelve large manufacturers. Financial Management, v. 15, p. 15-22, winter 1986

RUSSELL, C. Strategic industrial energy efficiency: reduce expenses, build revenues, and control risk. Energy Engineering: Journal of the Association of Energy Engineering, v. 102, p. 7-27, 2005

SANDBERG, P.; SÖDERSTRÖM, M. Industrial energy efficiency: the need for investment decision support from a manager perspective. Energy Policy, v. 31, p. 1623-1634, 2003. http://dx.doi.org/10.1016/ S0301-4215(02)00228-8

THOMPSOM, P. Evaluating energy efficiency investments: accounting for risk in the discounting process. Energy Policy, v. 25, n. 12, p. 989-996, 1997. http://dx.doi. org/10.1016/S0301-4215(97)00125-0

TUOMAALA, M.; HURME, M.; LEINO, A. Evaluating the efficiency of integrated systems in the process industry Case: Steam cracker. Applied Thermal Engineering, v. 30, p. 45-52, 2010 http://dx.doi.org/10.1016/j. applthermaleng.2009.06.024

UNIDAD DE PLANEACIÓN MINERO ENERGÉTICA - UPME. Herramientas para el análisis de caracterización de la eficiencia energética. Colômbia, 2006. 62 p.

ZHOU, H. et al. Study on probability distribution of prices in electricity market: A case study of zhejiang province, China. Communications in Nonlinear Science and Numerical Simulation, v. 14, p. 2255-2265, 2009. http://dx.doi.org/10.1016/j.cnsns.2008.04.020 